\title{
REPRESENTAÇÃO POLÍTICA: UM ESTUDO SOBRE O PERFIL DE ELEITORES, CANDIDATOS E ELEITOS À VEREANÇA EM 2012 NO LITORAL PARANAENSE ${ }^{1}$
}

\author{
Cleberson Rigo ${ }^{2}$ e Daniela Resende Archanjo $^{3}$
}

\begin{abstract}
RESUMO: O tema da representação política ganhou destaque nos últimos tempos em função da chamada crise de representatividade. No Brasil e em outras partes do mundo a insatisfação dos eleitores com o quadro de políticos que se apresenta para as disputas aos cargos resulta em esvaziamento da participação nas eleições, em crise de legitimidade de partidos e de governos, em falta de confiança dos cidadãos nas instituições representativas e em uma série de outras questões que são apontadas como limites próprios do sistema representativo. Dentre os modelos trazidos nos estudos sobre representação política encontramos o modelo de representação como "espelho" ou representatividade sociológica (COTTA, 1992), para o qual os espaços institucionalizados de representação, como a Câmara Municipal, por exemplo, reproduzem, em menor escala, as características do corpo social ao qual ela representa. Assim, o presente trabalho, de caráter exploratório-descritivo, se debruça sobre a análise do perfil de três categorias fundamentais aos processos eleitorais: eleitorado, candidatos e eleitos, considerando as variáveis: sexo, faixa etária, grau de instrução, partido e ocupação, apresentando proximidades e distanciamentos que existem entre elas.
\end{abstract}

Palavras-chave: representação política; elite política; litoral do Paraná

\section{INTRODUÇÃO}

O tema da representação política ganhou destaque nos últimos tempos em função da chamada crise de representatividade. No Brasil e em outras partes do mundo a insatisfação dos eleitores com o quadro de políticos que se apresenta para as disputas aos cargos resulta em esvaziamento da participação nas eleições, em crise de legitimidade de partidos e de governos, em falta de confiança dos cidadãos nas instituições representativas e em uma série de

\footnotetext{
${ }^{1}$ Este artigo é um aperfeiçoamento do Trabalho de Conclusão de Curso apresentado pelo então acadêmico Cleberson Rigo, sob a orientação da professora Daniela Resende Archanjo, ao curso de Gestão Pública do Setor Litoral da UFPR.

${ }^{2}$ Graduado em Gestão Pública pela UFPR, Setor Litoral.

${ }_{3}^{3}$ Professora do Curso de Gestão/Administração Pública da UFPR, Setor Litoral.
} 
outras questões que são apontadas como limites próprios do sistema representativo.

Em tempos em que parece ultrapassada (ao menos para a literatura especializada) a polarização entre representação e participação, embora permaneçam fortes as disputas e divergências político-ideológicas que permeiam as discussões sobre isso no campo da teoria democrática, o presente artigo parte de achados de trabalhos clássicos sobre o conceito de representação política para debruçar-se sobre a questão da existência (ou não) de espelhamento/identidade de perfil entre eleitores, candidatos e eleitos no processo eleitoral de 2012 dos sete municípios do litoral do Paraná.

Segundo Cotta (1992, p. 1102), estudiosos da Ciência Política apontam três modelos interpretativos alternativos sobre o conteúdo da função representativa e o papel dos representantes políticos: 1) a representação como relação de delegação; 2) como relação de confiança; 3) como "espelho" ou representatividade sociológica. Em linhas gerais, na primeira o representante recebe um mandato imperativo, que o vincula a exercer ou manifestar de modo exato a vontade do representado. A segunda pressupõe a autonomia do mandatário, que recebe do representado uma espécie de mandato fiduciário, sem caráter vinculante. Por fim, a representação como "espelho" tem o significado de representatividade, isto é, de semelhança ou de proporcionalidade da parte (representante) com o todo (representados).

O modelo de representação como "espelho" "concebe o parlamento como uma espécie de mapa, no qual se vê a imagem perfeita, embora em tamanho reduzido, da sociedade" (MIGUEL, 2005, p. 35). "Diferentemente dos dois primeiros [modelos de representação] é centrado mais sobre o efeito de conjunto do que sobre o papel de cada representante. Ele concebe o organismo representativo como um microcosmos que fielmente reproduz as características do corpo político" (COTTA, 1992, p. 1102). O modelo de representação como representatividade apresenta-se como uma proposta de garantia da participação política dos diferentes grupos sociais. Para tanto, são apontados como mecanismos de promoção da participação política a seleção aleatória dos governantes e (ou) a reserva de vagas para grupos marginalizados. 
Contemporaneamente, a prática de exigência de cotas de mulheres nas instituições públicas, incluído aí o Parlamento, segue essa linha de entendimento, garantindo, por meio da reserva de vagas, a participação política das mulheres, assim como de outros grupos tradicionalmente excluídos do poder. A identidade entre representante e representados é apontada como um meio de suscitar a participação ativa e inclusiva do eleitorado no debate político, mantendo conectadas a sociedade civil e a esfera pública. Young (2006) ressalta, entretanto, as dificuldades da relação identitária, uma vez que os indivíduos podem identificar-se em relação a alguns aspectos e divergir em relação a outros, o que produziria ruídos na representação. ${ }^{4}$

O presente estudo procura retratar o perfil dos vereadores eleitos em 2012 para ocupar as cadeiras das Câmaras Municipais dos municípios do litoral paranaense, comparando o perfil dos eleitos com o perfil dos candidatos que não obtiveram êxito na disputa eleitoral e comparando também o perfil de ambos com o perfil dos eleitores da região. São objeto de estudo os sete municípios do litoral paranaense: Antonina, Guaraqueçaba, Guaratuba, Matinhos, Morretes, Paranaguá e Pontal do Paraná. De acordo com dados do TSE, os municípios do litoral paranaense contaram com um eleitorado apto a votar de 207.569 pessoas nas eleições de 2012 (TSE, 2012, IPARDES 2012).

Trata-se de um levantamento junto a fontes secundárias, tais como: TSE (Tribunal Superior Eleitoral), TRE-PR (Tribunal Regional Eleitoral do Paraná), IBGE (Instituto Brasileiro de Geografia e Estatística) e IPARDES (Instituto Paranaense de Desenvolvimento Econômico e Social). Este trabalho, a partir de uma abordagem exploratória e descritiva, analisa cinco variáveis: 1) Sexo; 2) Faixa etária; 3) Grau de instrução; 4) Partido político; e 5) Ocupação; buscando desenhar o perfil de três categorias de atores importantes em estudos eleitorais: eleitores, candidatos e eleitos. Em relação ao perfil dos eleitores, apenas as variáveis Sexo, Faixa etária e Grau de instrução compuseram a análise, visto a dificuldade para equiparar os bancos de dados do TSE com as informações

\footnotetext{
4 Toda a discussão aqui apresentada sobre o conceito de representação política é um recorte do que consta em: ARCHANJO, Daniela Resende. Representação política: um diálogo entre a prática e a teoria. In Revista de Sociologia Política, Curitiba, v. 19, n. 38, p. 65-83, fev. 2010.
} 
disponíveis sobre ocupação da população em bancos como os do Ministério do Trabalho e Emprego, do IBGE e do IPARDES.

\section{DAS CÂMARAS MUNICIPAIS}

Para uma compreensão do processo político municipal é indispensável entendermos o que são e o que fazem as Câmaras Municipais.

Corralo (2008) relembra que a partir da Constituição Federal de 1988 os municípios foram considerados entes federados, tendo adquirido um grau elevado de autonomia no que concerne à sua auto-organização, à autonomia política, administrativa, legislativa e financeira. O autor ressalta que "o conceitochave para compreensão da autonomia municipal é o 'interesse local', assim definido no art. da CF" (CORRALO, 2008, p. 26).

Importa destacar que o conceito de "interesse local" não se restringe à busca do interesse privativo do espaço geográfico do município, mas abrange a compreensão do município como parte de um determinado Estado e da União.

Cumpre anotar a importância das Câmaras Municipais para a efetivação das autonomias municipais, visto que a elas cabe o exercício de importantes funções, como: legislar, fiscalizar, assessorar etc.

\section{DOS MUNICÍPIOS DO LITORAL PARANAENSE}

O litoral paranaense é constituído por sete municípios: Antonina, Guaraqueçaba, Guaratuba, Matinhos, Morretes, Paranaguá e Pontal do Paraná. A tabela 1 mostra alguns dados socioeconômicos da região que denotam semelhanças e diferenças entre os mesmos.

Nota-se que a economia do litoral paranaense é bastante expressiva em sua totalidade, quando falamos do PIB (Produto Interno Bruto), entretanto é de se salientar que o município de Paranaguá possui um PIB muito mais expressivo que os demais, pelo fato de estar em seu município um dos portos mais importantes para o escoamento da produção agrícola brasileira. Entretanto, através do índice Gini, vemos que os municípios de Paranaguá, Antonina, Guaratuba e Morretes possuem um índice de desigualdade econômica mediano, embora os índices destes municípios sejam na maior parte inferiores ao índice 
médio no Brasil em 2008. Este índice Gini é um instrumento usado para medir a disparidade de renda existente entre os indivíduos, onde o índice poderá variar de zero a um ou de zero a cem, onde o valor zero representa uma perfeita distribuição de renda (IPARDES, 2014; SALVADOR, 2010)

É visível ainda a disparidade entre os municípios no que tange ao IDH (Índice de Desenvolvimento Humano). Os municípios de Matinhos e de Paranaguá estão no ranking dos cinqüenta municípios do estado com maior IDH, todavia temos o município de Guaraqueçaba ocupando a posição 396 do ranking estadual, encontrando-se entre um dos quatro municípios do ranking do estado com menor IDH (HOROCHOVSKI, 2012, p.2; IPARDES, 2010).

TABELA 1

DADOS SOCIOECONÔMICOS DOS MUNICÍPIOS DO LITORAL PARANAENSE.

\begin{tabular}{|l|r|r|r|r|r|r|}
\hline & \multicolumn{1}{|c|}{$\begin{array}{c}\text { PIB per } \\
\text { Capita } \\
(\mathrm{R} \$ 1,00)^{*}\end{array}$} & $\begin{array}{c}\text { PIB a } \\
\text { Preços } \\
\text { Correntes } \\
(\mathrm{R} \$\end{array}$ & $\begin{array}{c}\text { Área } \\
\text { Territorial } \\
\left(\mathrm{km}^{2}\right)^{\star *}\end{array}$ & $\begin{array}{c}\text { População } \\
\text { Estimada } \\
\text { (IBGE) } \\
\text { Residentes } \\
\text { em 01/07 } * \star\end{array}$ & $\begin{array}{c}\text { Índice } \\
\text { Gini - } \\
\text { Geral *** }\end{array}$ & $\begin{array}{c}\text { IDH } \\
\text { Municipal } \\
\text { (IDH-M) } \\
\star * \star\end{array}$ \\
\hline Antonina & 11.791 & 222.252 & 876,551 & 19.414 & 0,55 & 0,687 \\
\hline Guaraqueçaba & 10.131 & 79.114 & $2.315,73$ & 7.988 & 0,49 & 0,587 \\
\hline Guaratuba & 12.095 & 397.043 & $1.328,48$ & 34.767 & 0,56 & 0,717 \\
\hline Matinhos & 13.461 & 406.783 & 116,544 & 32.148 & 0,48 & 0,743 \\
\hline Morretes & 10.269 & 162.092 & 687,541 & 16.381 & 0,53 & 0,686 \\
\hline Paranaguá & 70.251 & 10.007 .402 & 806,225 & 149.467 & 0,52 & 0,750 \\
\hline $\begin{array}{l}\text { Pontal do } \\
\text { Paraná }\end{array}$ & 12.638 & 276.986 & 202,159 & 23.816 & 0,51 & 0,738 \\
\hline
\end{tabular}

* Referente ao ano 2012

** Referente ao ano 2014

*** Referente ao ano 2010

Fonte: Elaboração do autor a partir dos dados do IPARDES

\section{DO PROCESSO ELEITORAL NO LITORAL PARANAENSE}

As Câmaras Municipais do litoral paranaense apresentam disparidade quanto ao número de processos e/ou atividades eleitorais já vividos no que tange à escolha dos representantes no Executivo e do Legislativo. A tabela 2 permite a identificação do quantitativo de eleitores e candidatos aptos a votarem e a 
serem votados na eleição de 2012 no litoral paranaense, assim como, a quantidade de vereadores eleitos na mesma eleição. Conforme se vê na referida tabela, temos nas eleições de 2012 no litoral paranaense 207.569 eleitores aptos a votarem que escolheram seus representantes entre 977 candidatos aptos. Foram ocupadas 83 cadeiras então disponíveis nas Câmaras Municipais dos sete municípios da região.

Nota-se na tabela 2 que quando comparado o número de candidatos com o número de vagas disponível à vereança, por município, somente Guaraqueçaba não apresenta um número maior do que a média nacional e estadual. Isto significa que temos, de modo geral, os municípios do litoral do Paraná têm muitos candidatos concorrendo às eleições locais, mais do que a média nacional e estadual.

TABELA 2

ELEITORADO, CANDIDATOS E VEREADORES ELEITOS, POR MUNICÍPIO, EM 2012

\begin{tabular}{|l|r|r|r|r|r|r|}
\hline & Eleitorado & Candidatos & Eleitos & $\begin{array}{c}\text { Candidato } \\
\text { por vaga }\end{array}$ & $\begin{array}{c}\text { Eleitorado por } \\
\text { Candidato }\end{array}$ & $\begin{array}{c}\text { Eleitorado } \\
\text { por Eleito }\end{array}$ \\
\hline Brasil & 140.394 .103 & 415.018 & 57.430 & 7,23 & 338,28 & 2444,61 \\
\hline Paraná & 7.727 .727 & 27.240 & 3.866 & 7,05 & 283,69 & 1998,89 \\
\hline Antonina & 16.142 & 131 & 11 & 11,91 & 123,22 & 1467,45 \\
\hline Guaraqueçaba & 6.959 & 62 & 9 & 6,89 & 112,24 & 773,22 \\
\hline Guaratuba & 25.483 & 140 & 13 & 10,77 & 182,02 & 1960,23 \\
\hline Matinhos & 26.425 & 126 & 11 & 11,45 & 209,72 & 2402,27 \\
\hline Morretes & 14.720 & 115 & 11 & 10,45 & 128,00 & 1338,18 \\
\hline Paranaguá & 101.047 & 279 & 17 & 16,41 & 362,18 & 5943,94 \\
\hline Pontal do Paraná & 16.793 & 124 & 11 & 11,27 & 135,42 & 1526,63 \\
\hline
\end{tabular}

Fonte: Elaboração do autor a partir de dados do TSE, eleições de 2012.

\section{DO PERFIL DOS LEGISLADORES MUNICIPAIS E SUA SEMELHANÇA COM O PERFIL DOS CANDIDATOS E DO ELEITORADO LOCAL}

$\mathrm{Na}$ comparação entre o perfil dos candidatos e dos vereadores eleitos, foram confrontadas cinco variáveis: 1) Sexo; 2) Faixa etária; 3) Grau de instrução; 4) Partido político; e 5) Ocupação. No que diz respeito ao perfil dos eleitores, apenas três variáveis foram consideradas: 1) Sexo; 2) Faixa etária e 3) Grau de instrução. 
A primeira variável trabalhada foi à variável sexo ${ }^{5}$, que, aplicada às três categorias nos permitiu elaborar o Gráfico 1. Conforme demonstra o gráfico, a porcentagem de pessoas do sexo feminino e do sexo masculino na categoria eleitorado é praticamente a mesma, entretanto, em relação à média dos candidatos, a situação é completamente diferente, pois temos $68,57 \%$ de homens disputando as vagas à vereança e apenas 31,42\% de mulheres.

A desproporcionalidade entre os dois sexos quando falamos de vereadores eleitos é maior ainda e nem um pouco proporcional ao perfil do eleitorado. As Câmaras Municipais do litoral paranaense são compostas predominantemente por pessoas do sexo masculino. No caso do município de Matinhos, nenhuma cadeira do legislativo foi ocupada por pessoa do sexo feminino em 2012.

Também importa destacar o papel da Lei no.12.034, de 29 de setembro de 2009, como fator que interfere no número de mulheres que aparecem como candidatas às vagas das Câmaras Municipais. A referida lei estipula uma cota mínima de $30 \%$ e máxima de $70 \%$ de diferença de sexo entre todo o contingente de candidatos de cada partido. Para cumprir a exigência legal os partidos têm reservado uma cota mínima de $30 \%$ para a inscrição de mulheres. Um artigo disponibilizado pelo Governo Federal discute alguns fatores que evidenciam o porquê da não candidatura de mulheres por partido em números mais expressivos e porque o sexo feminino não elege as mulheres. Dentre estes fatores aparecem os recursos financeiros dos partidos para as candidatas, a não aceitação da mulher como potencial político, o recrutamento de mulheres sem capital político, entre outros (BRASIL, 2014). Nóbrega (2006) aponta inúmeros obstáculos que bloqueiam a participação da mulher na política de fato, como: a conquista de espaço e a difícil tarefa da mulher de demonstrar sua capacidade; as questões estruturais da sociedade, que restringem o sexo feminino ao espaço privado; o fato da mulher muitas vezes não incorporar sua inserção no espaço político; a breve inserção da mulher na política, entre outros.

\footnotetext{
${ }^{5}$ Registramos que $0,107 \%$ de todo o contingente do eleitorado não declarou o seu sexo.
} 
GRÁFICO 1

SEXO DO ELEITORADO, CANDIDATOS E VEREADORES ELEITOS - LITORAL PARANAENSE, ELEIÇÕES 2012

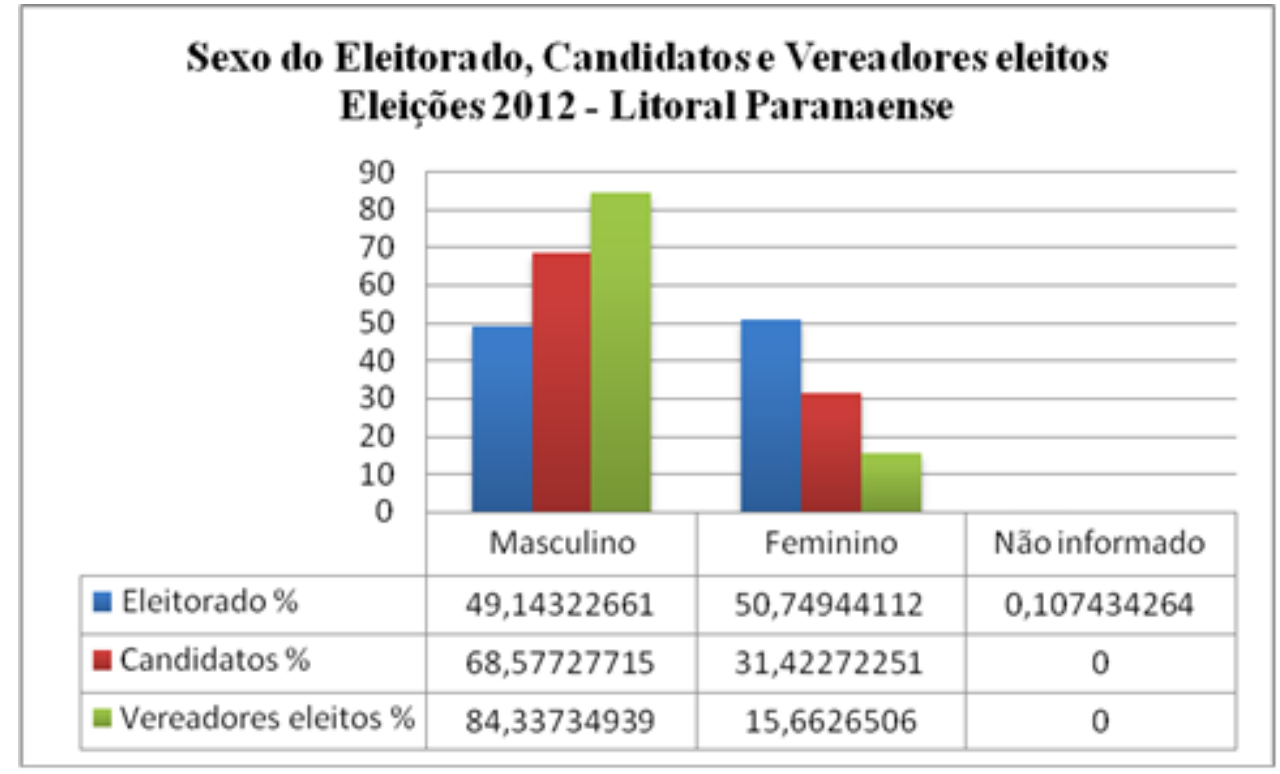

Fonte: Elaboração do autor a partir dos dados do TSE.

A segunda variável trabalhada foi a faixa etária dos eleitores, candidatos e vereadores eleitos, conforme demonstra o gráfico 2.

Percebe-se que mais de $66 \%$ dos eleitores tem entre 25 e 59 anos, não havendo grande dissimilaridade na distribuição entre as faixas etárias entre 25 a 34 anos, 35 a 44 anos e 45 a 59 anos. Todavia, quando analisamos o perfil dos candidatos, percebemos que a maior parte dos candidatos situa-se na faixa etária dos 45 a 59 ocupando quase $46 \%$ de todo o contingente, seguidos da faixa etária dos 35 aos 44 anos com 29,48\%. Ou seja, poucos são os jovens que se apresentam para a disputa eleitoral. No que se refere ao perfil de idade dos vereadores eleitos, o gráfico se assemelha ao do perfil dos candidatos, sendo maior o número de eleitos na faixa entre 45 a 59 anos de idade.

Tais achados podem remeter a diferentes discussões, muitas delas já enfrentadas pela literatura, tais como a questão da cultura política entre os jovens (BAQUERO e BAQUERO, 2007; AZEVEDO et al, 2009; GOHN, 2017). 
GRÁFICO 2

FAIXA DO ELEITORADO, CANDIDATOS E VEREADORES ELEITOS, ELEIÇÕES 2012 LITORAL PARANAENSE

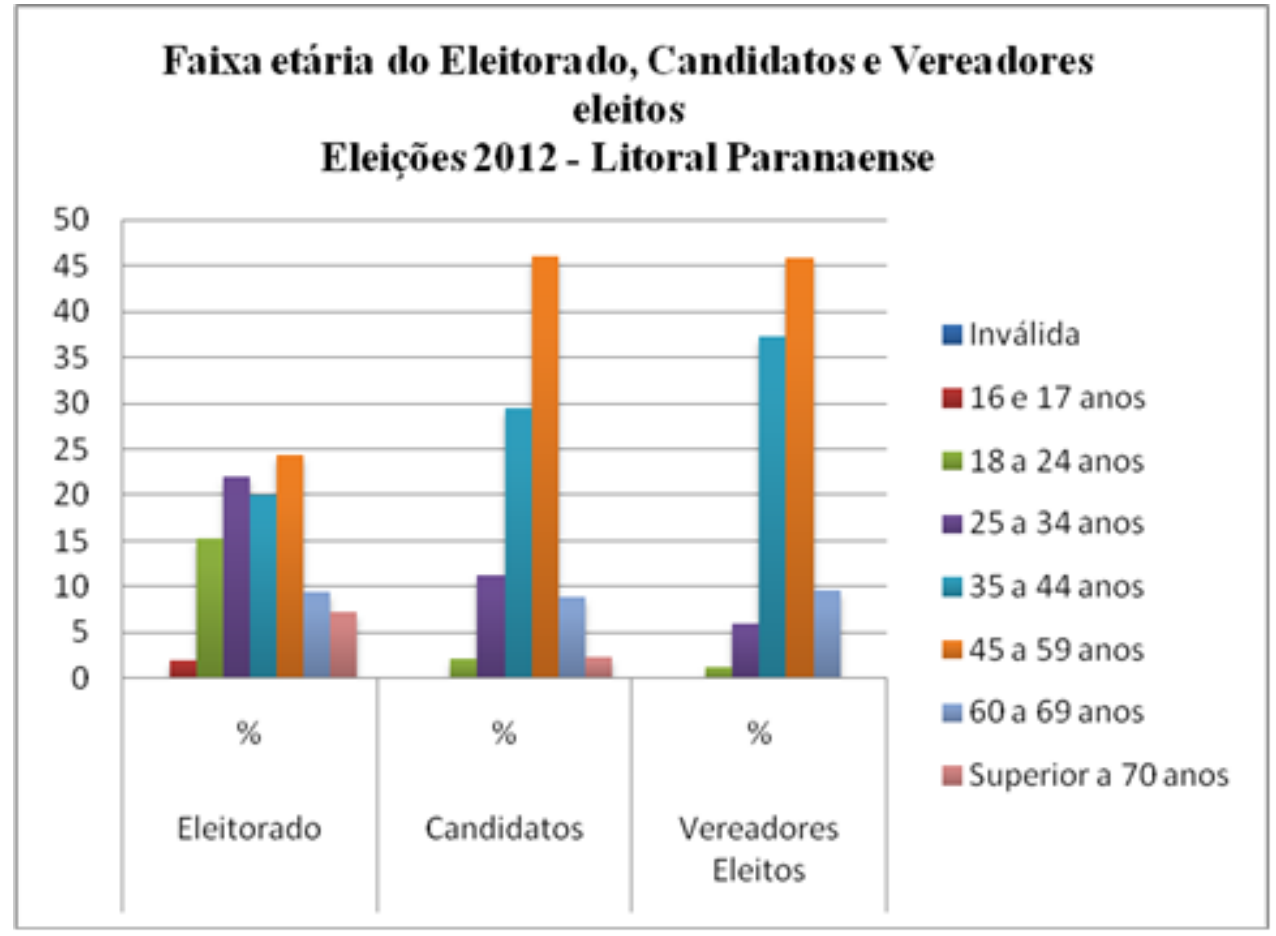

Fonte: Elaboração do autor a partir dos dados do TSE.

A terceira variável trabalhada foi o grau de instrução. Vale ressaltar a importância do grau de instrução, ou seja, o nível de escolaridade, como elemento essencial à construção do capital humano. Um alto nível de capital humano está associado a um nível mais elevado de conhecimento dos atores, nível adquirido por meio da educação e que se relaciona com os índices de desenvolvimento de uma determinada região. "A educação é um fator importante para o crescimento econômico do país, a acumulação do capital humano possibilita melhorias no fator trabalho aumentando os níveis de produtividade e renda dos indivíduos, assim, a escolaridade está associada ao crescimento econômico dentro da teoria do capital humano" (PEREIRA, apud FIGUEIREDO; NAKABASHI, 2005).

A análise do gráfico 3 demonstra o alto índice de eleitores com ensino fundamental incompleto, com porcentagens que chegam a $36,38 \%$ de todo 0 contingente. Outro índice que detém uma porcentagem mais elevada é o de eleitores com ensino médio incompleto, demonstrando o baixo grau de 
escolarização da população. Entretanto, vê-se que o grau de instrução com maior porcentagem na categoria de candidatos é o de pessoas com ensino médio completo $(35,21 \%)$, seguido de pessoas com ensino superior completo $(20,78 \%)$. Vale ressaltar que os municípios de Pontal do Paraná e o de Paranaguá possuem em média $25 \%$ de candidatos de seus respectivos municípios com ensino superior completo, enquanto Guaraqueçaba é o que possui menos candidatos nesta situação, com apenas 8,06\%.

Quando analisamos o gráfico 3, mais especificamente a categoria de vereadores eleitos, nos deparamos com a prevalência de atores com grau de instrução de ensino médio completo, repetindo basicamente a mesma proporcionalidade apresentada na categoria de candidatos. Ainda é de se ressaltar a ascensão de vereadores com ensino superior completo quando comparados com a categoria de candidatos.

\section{GRÁFICO 3}

GRAU DE INSTRUÇÃO DO ELEITORADO, CANDIDATOS E VEREADORES ELEITOS, ELEIÇÕES 2010- LITORAL PARANAENSE

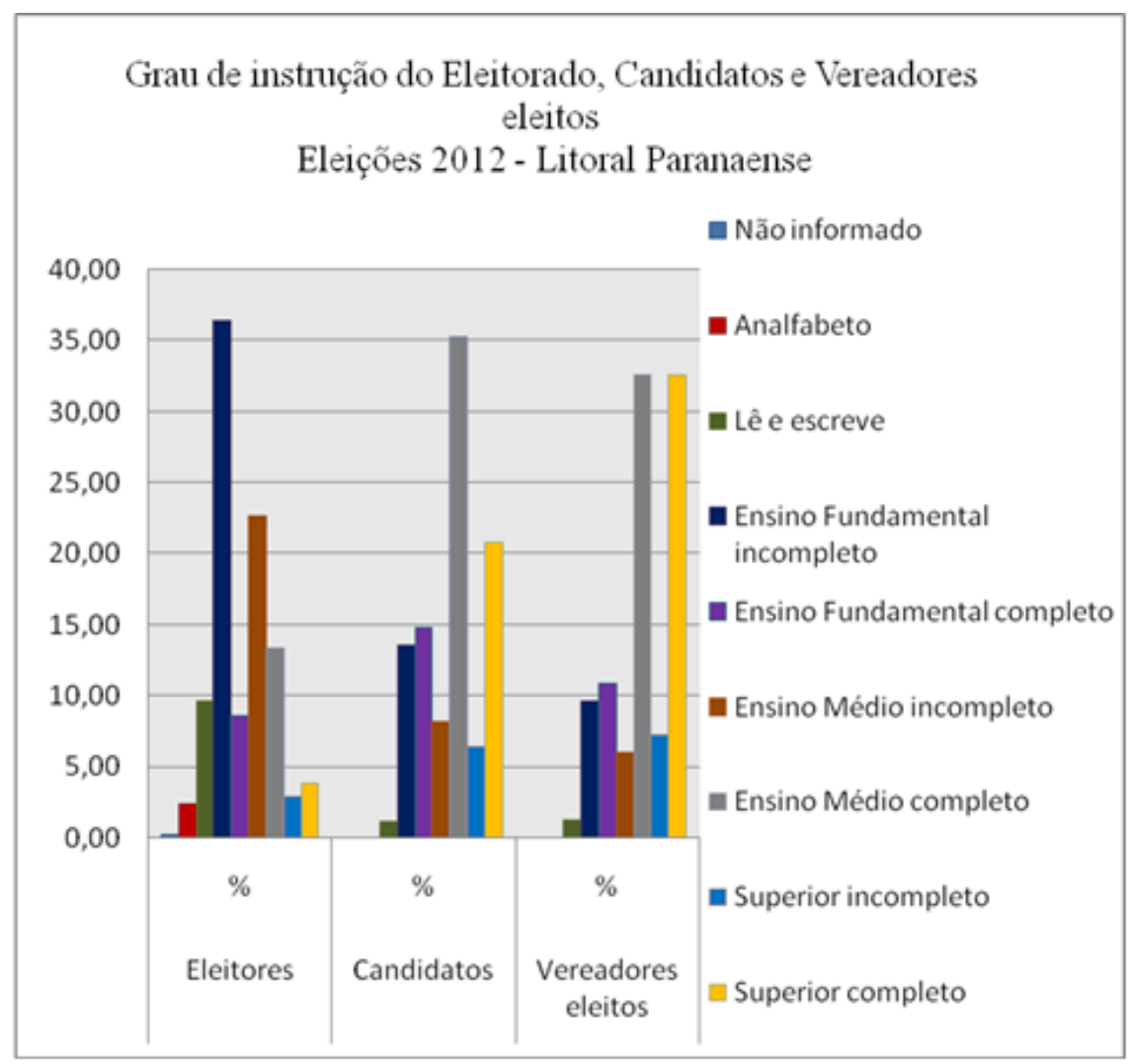

Fonte: Elaboração do autor a partir dos dados do TSE. 
A quarta variável investigada foi o partido político, variável que só se aplica a candidatos e a vereadores eleitos. A compreensão desta variável é importante para conseguirmos retratar o perfil dos candidatos e dos vereadores eleitos, pois cada partido se posiciona de uma determinada forma em relação a temas como: igualdade, liberdade, capitalismo, interferência governamental, entre outros. $O$ presente estudo parte do pressuposto que aos partidos correspondem a diferentes posicionamentos ou eixos ideológicos.

Sabemos que categorizações de partidos como sendo de direita, esquerda ou centro são bastante discutíveis, havendo uma diversidade de classificações apresentada na literatura. Souza (2012, p.13) discute "Padrões geográficos das coligações eleitorais no Brasil: uma análise pela perspectiva ideológica dos partidos políticos". Neste trabalho são apresentados os partidos de acordo com seu eixo ideológico. De acordo com o referido autor, "na determinação da ideologia partidária, os partidos foram classificados de acordo com a aproximação programática existente entre eles. Assim, o eixo ideológico da direita passou a contar com o seguinte conjunto de partidos: DEM (PFL), PHS, PP (PPB), PR (PL/PRONA), PRP, PRTB, PSC, PSDC, PSL, PTB, PTC, PT do B, PTN. O centro: PMDB E PSDB. E a esquerda: PCB, PC do B, PCO, PDT, PMN, PPS, PRB, PSB, PSOL, PSTU, PT, PV", e ainda o PSD de direita (SOUZA, 2012, p. 13).

No gráfico 4 podemos verificar os posicionamentos ideológicos de todos os partidos do litoral do Paraná que participaram do processo eleitoral nas eleições de 2012 , na qual temos $56 \%$ de partidos de direita ${ }^{6}, 32 \%$ de esquerda $^{7}$ e $8 \%$ de centro ${ }^{8}$. Os $4 \%$ restantes se referem a um determinado partido ${ }^{9}$ que não foi enquadrado em nenhuma dessas posições, pois o artigo de Souza (2012), que foi usado como referência, não o contempla, e o uso de outro autor não seria apropriado visto que há diferenças na literatura na classificação dos posicionamentos ideológicos dos partidos.

\footnotetext{
${ }^{6}$ Partidos de direita: PTN, PR, PSL, PSC, PTC, DEM, PHS, PRP, PRTB, PSD, PTB, PP, PSDC E PT do B.

${ }^{7}$ Partidos de esquerda: PMN, PC do B, PDT, PSB, PV, PPS, PT e PRB.

${ }^{8}$ Partidos de centro: PSDB E PMDB

9 Partido não mencionado pelo autor: PPL
} 
GRÁFICO 4

POSICIONAMENTO IDEOLÓGICO DOS PARTIDOS ELEIÇÕES 2012- LITORAL PARANAENSE.

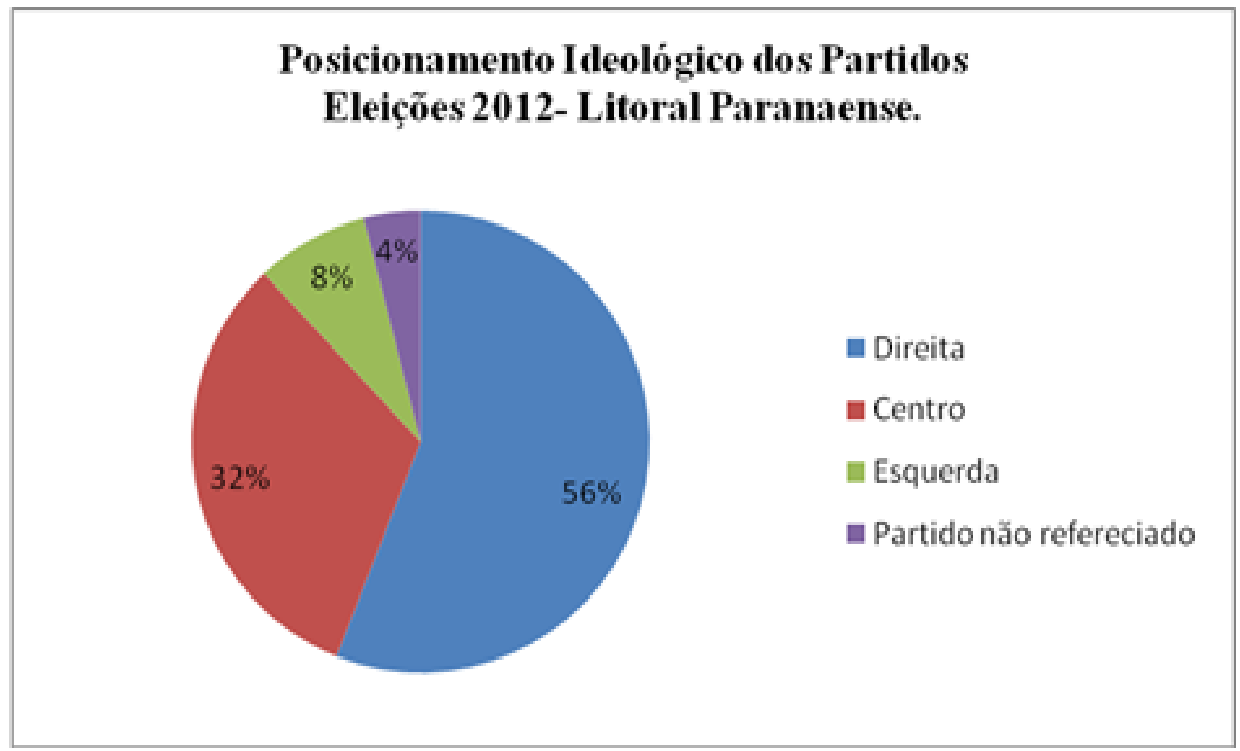

Fonte: Elaboração do autor a partir dos dados do TSE e de SOUZA (2012).

Quanto à categoria de candidatos, no que diz respeito ao posicionamento ideológico de cada partido, podemos observar no gráfico 5 que os partidos pertencentes ao eixo ideológico da direita lançaram $45,04 \%$ do total de candidatos e conquistaram $46,99 \%$ das vagas disponíveis. Os partidos que correspondem ao eixo ideológico da esquerda lançaram $37,56 \%$ do total de candidatos e conquistaram $34,94 \%$ das vagas ofertadas. No que se refere aos partidos de centro, temos $16,68 \%$ dos candidatos à disputa e $16,87 \%$ de cadeiras ocupadas nas Câmaras de leis do litoral paranaense. Ainda temos 0,72\% dos candidatos pertencentes ao partido ao qual o autor do artigo usado como base não faz referência. Este mesmo partido conseguiu 1,20\% das cadeiras em disputa. 
GRÁFICO 5

POSICONAMENTO IDEOLÓGICO DOS PARTIDOS E DAS CATEGORIAS DE CANDIDATOS

E DE VEREADORES ELEITOS ELEIÇÕES 2012- LITORAL PARANAENSE.

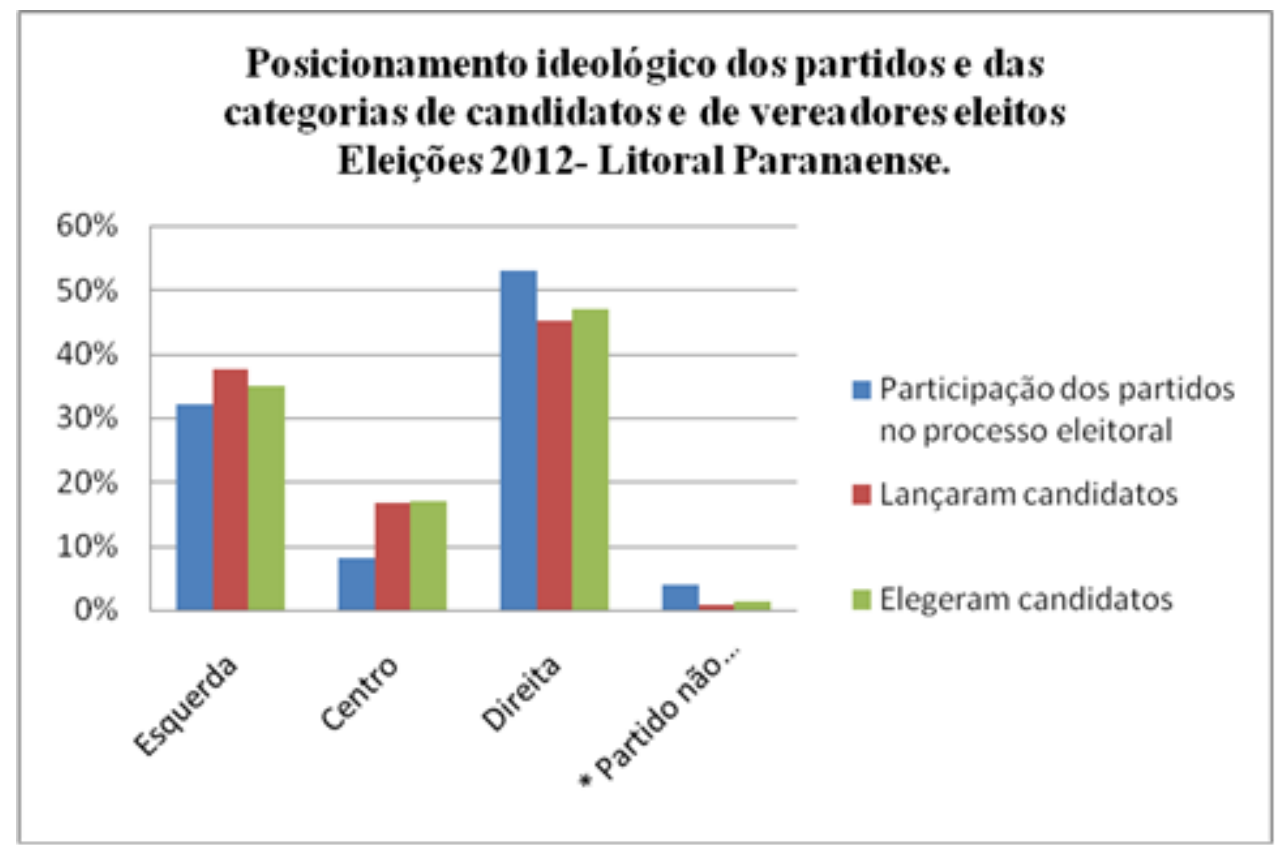

Fonte: Elaboração do autor a partir dos dados do TSE e de SOUZA (2012).

A tabela 3 evidencia os dez partidos que mais apresentaram candidatos à disputa à vereança em 2012 nos municípios do litoral paranaense, correspondendo a $66,43 \%$ do total dos candidatos. Os demais quinze partidos somaram 33,57\%.

Os dez ${ }^{10}$ partidos mais expressivos no quesito de conquista de vagas nas câmaras de leis do litoral paranaense conquistaram, juntos, 77,11\% de todas as vagas disponíveis, totalizando 64 cadeiras conquistadas das 83 ofertadas. Os $22,89 \%$ restantes foram divididas entre os outros dez partidos que conseguiram conquistar no mínimo uma vaga.

Por mais que os dez partidos mais expressivos juntos possuam porcentagens expressivas referentes aos números de candidatos à disputa e de vereadores eleitos, o princípio da pluralidade de partidos encontra-se presente, o que para muitos autores é de suma importância em um processo eleitoral, visto

\footnotetext{
${ }^{10}$ Quando comparado aos sete maiores partidos do Brasil citados por RIBEIRO (2014, p. 2) e por outros autores, apenas o PP (Partido Progressista) não está entre os dez partidos mais expressivos nas eleições de 2012 no litoral paranaense.
} 
que este pluripartidarismo está atrelado à representação dos mais variados grupos da sociedade (organizados ou não) e aos princípios e valores de cada partido. Junior (2011) descreve esta sociedade diversificada como uma sociedade plural, "ideologicamente oposta à unificação de poder ou à unanimidade totalitária" (JÚNIOR, 2011, p. 37).

Entretanto, muitos autores discutem empecilhos que a pluralidade partidária pode ocasionar nas arenas de poder, fazendo críticas aos partidos que nascem sem posição ideológica clara e distinta dos demais partidos existentes. Rodrigues (2014, apud Filho, 2008) denomina estes partidos de "corpos sem almas".

Esta fragmentação partidária não significa que haja a fragmentação social, entretanto este número gigantesco de partidos se submete a coalizões e a barganhar com inúmeros partidos, o que torna a governabilidade praticamente sucumbida e o avanço das discussões dos processos nas arenas intermináveis (RODRIGUES, 2014, apud SILVA et al, 1999).

TABELA 3

DEZ PARTIDOS MAIS EXPRESSIVOS NAS CATEGORIAS DE CANDIDATOS E VEREADORES ELEITOS

\begin{tabular}{|c|c|c|c|}
\hline & Candidatos & & $\begin{array}{l}\text { Vereadores } \\
\text { eleitos }\end{array}$ \\
\hline Partido & $\%$ & Partido & $\%$ \\
\hline PSDB & 9,01 & DEM & 10,84 \\
\hline PMDB & 7,68 & PDT & 10,84 \\
\hline DEM & 6,96 & PSC & 9,64 \\
\hline PDT & 6,76 & PMDB & 8,43 \\
\hline PSC & 6,55 & PSDB & 8,43 \\
\hline PV & 6,24 & PSD & 7,23 \\
\hline PT & 6,14 & PT & 7,23 \\
\hline PSB & 6,04 & PPS & 4,82 \\
\hline PPS & 5,53 & PSB & 4,82 \\
\hline PSL & 5,53 & PTB & 4,82 \\
\hline
\end{tabular}

Fonte: Elaboração do autor a partir dos dados do TSE.

Ainda no que se refere aos partidos, Nicolau (2005) discorre em seu trabalho sobre o número efetivo de partidos por Câmaras Municipais ou arenas 
legislativas municipais. A partir deste trabalho procurou-se estabelecer a média de partidos efetivos no litoral paranaense nas eleições de 2012. Para se chegar a esta média primeiramente foi calculado individualmente o índice de HerfindalHirschmam $(\mathrm{HH})$, para o qual tem-se a seguinte fórmula de cálculo: $\Sigma p^{2} i$. Posteriormente foi calculado o índice efetivo de partidos $(\mathrm{N})$, para mensurar a dispersão/concentração destes partidos. LAAKSO e TAAGEPERA (1979) em um determinado momento propuseram um índice que suprisse este anseio, então, foi criada uma fórmula, usando como base o índice Herfindal- Hirschmam $(\mathrm{HH})$, surgindo assim a seguinte formula: 1/ $\mathrm{HH}$. (NICOLAU, 2005 apud LAAKSO, TAAGEPERA (1979).

A partir destas fórmulas, no que se refere ao número efetivo de partidos (N) no litoral paranaense, temos uma média litorânea de 7,17. Ainda é de se ressaltar que quanto ao número de partidos efetivos $(\mathrm{N})$ por município ${ }^{11}$ do litoral paranaense, temos a maioria de municípios com grande número de partidos efetivos, independentemente da proporção de cadeiras ofertadas por cada casa de leis. Este formato é fruto do sistema eleitoral proporcional de lista aberta.

A quinta e última variável trabalhada buscando estabelecer o perfil das câmaras de leis do litoral paranaense, é a variável ocupação. A visualização desta variável tem o propósito de evidenciar quais são as principais ocupações dos candidatos e vereadores eleitos. A tabela 4 apresenta as dez ocupações mais expressivas da categoria de candidatos e de vereadores eleitos, lembrando que as ocupações dos candidatos e consequentemente dos vereadores eleitos, são auto declaradas, sendo comum que pessoas exerçam mais que uma atividade profissional e declararem a que melhor lhes convêm.

As dez ocupações mais expressivas da categoria de candidatos, juntas, se aplicam a $58,34 \%$ do total de candidatos, totalizando assim 570 candidatos que declararam alguma dentre as dez ocupações apresentadas na tabela. Das

\footnotetext{
${ }^{11}$ Numero de partidos efetivos por município: Antonina (5,761895); Guaraqueçaba $(6,230769)$; Guaratuba (7,347825); Matinhos (4,481482); Morretes (7,11764); Paranaguá $(9,965517)$ e Pontal do Paraná $(9,307693)$.
} 
dez ocupações mais expressivas ${ }^{12}$ podemos destacar a de "servidor público municipal". A presença desta ocupação dentre as dez primeiras não surpreende, tendo em vista que a atuação no serviço público aproxima a pessoa das questões municipais, sendo muitas vezes uma porta de entrada para a vida política. Além disso, o serviço público comporta grande parte dos trabalhadores do litoral paranaense. O litoral paranaense possui em sua totalidade 10.501 indivíduos que trabalham na Administração pública direta e indireta (IPARDES, 2015), o que corresponde a 5,6\% de seu eleitorado.

Esta boa colocação dos servidores públicos municipais entre as dez ocupações não se restringe somente à categoria de candidatos, mas se reflete também na categoria de vereadores eleitos. Outro ponto que é intrigante, mas esperado, é a variação da ocupação de vereador nas categorias de candidatos e de vereadores eleitos. Quando tratamos dos candidatos, vemos que a ocupação de "vereador" está na décima posição, com apenas 2,55\% do total de candidatos. No entanto, quando analisamos a categoria de vereadores eleitos, constatamos que $13,25 \%$ deles declararam como ocupação a de "vereador", apontando para os casos de reeleição. É interessante anotar que alguns, apesar de terem ocupado o cargo de vereador na legislatura imediatamente anterior, não declaram esta como sendo a sua ocupação.

As dez ocupações mais expressivas na categoria de vereadores eleitos, juntas, correspondem a $65,06 \%$ de todas as vagas, assim ocupando 54 cadeiras das 83 ofertadas nos sete municípios litorâneos do Paraná. Ainda é de se ressaltar que das dez ocupações mais expressivas das categorias de candidatos e de vereadores eleitos apenas três ocupações não se repetem entre as duas categorias.

Ainda em relação às ocupações de candidatos e de eleitos, destaca-se a predominância de ocupações que possuem bastante visibilidade no contexto econômico do município. Quanto à ocupação de dona de casa estar entre as dez ocupações mais expressivas na categoria de candidatos e não haver uma repetição na categoria de vereadores eleitos pode-se atribuir este fato ao

\footnotetext{
12 Conforme demonstra a tabela, $11,46 \%$ dos candidatos auto-declararam no campo ocupação "outros", sendo este o maior percentual. No entanto, dentre as ocupações especificadas, destaca-se a de servidor público municipal.
} 
recrutamento de mulheres sem capital político, associado a não visibilidade das mulheres como um ator em potencial pelos partidos, eles acabam por restringir os recursos destinados as campanhas das mulheres, assim a conquista pelo cargo de vereador pelo sexo feminino fica cada vez mais distante (BRAZIL, 2014).

TABELA 4

DEZ OCUPAÇÕES MAIS EXPRESSIVAS POR CANDIDATOS E VEREADORES ELEITOS NAS ELEIÇÕES DE 2012 EM \%

\begin{tabular}{|l|r|l|r|}
\hline \multicolumn{2}{|c|}{ Candidatos } & \multicolumn{2}{c|}{ Vereadores eleitos } \\
\hline Ocupação & $\%$ & Ocupação & $\%$ \\
\hline Outros* & 11,46366 & Vereador & 13,25301 \\
\hline Servidor Público Municipal & 10,23541 & Comerciante & 12,04819 \\
\hline Comerciante & 9,109519 & Servidor Público Municipal & 10,84337 \\
\hline Empresário & 7,267144 & Administrador & 4,819277 \\
\hline & & & \\
Dona de Casa & 5,42477 & Servidor Público Estadual & 4,819277 \\
\hline Aposentado (Exceto Servidor Público) & 3,991812 & Empresário & 4,819277 \\
\hline Professor de Ensino Médio & 3,172978 & Agente Administrativo & 3,614458 \\
\hline Administrador & 2,558854 & Agricultor & 3,614458 \\
\hline Pescador & 2,558854 & Pescador & 3,614458 \\
\hline Vereador & 2,558854 & Outros* & 3,614458 \\
\hline * Engloba os que não se enquadraram em nenhuma das ocupações apresentadas pelo TSE. \\
\hline
\end{tabular}

Fonte: Elaboração do autor a partir dos dados do TSE.

\section{CONSIDERAÇÕES FINAIS}

Através da visualização e da interpretação das tabelas e dos gráficos apresentados no decorrer do trabalho, conseguimos alcançar os anseios da pesquisa. Quanto à variável sexo, podemos destacar a predominância do sexo masculino tanto no que se refere aos candidatos quanto no que se refere aos eleitos às Câmaras Municipais do litoral paranaense. Reproduzindo o que apontam os estudos sobre a participação de mulheres no poder vemos que, apesar de serem maioria entre os eleitores, as mulheres são minoria entre candidatos e vereadores eleitos. 
Quanto à variável faixa etária, podemos destacar a predominância de candidatos e de vereadores eleitos na faixa de 35 a 59 anos, chamando a atenção para a pouca participação de jovens na política, apesar do grande número de jovens na sociedade.

Em relação à variável grau de instrução podemos evidenciar a alta porcentagem de vereadores eleitos com ensino superior completo, comparados à categoria de candidatos e de eleitores, embora esta proporção de indivíduos ainda seja baixa se pensarmos o potencial da alta escolaridade para 0 desenvolvimento de um município. Grande parte dos candidatos possui ensino médio completo, seguido de uma pequena porcentagem com ensino superior completo. O perfil dos eleitores não se reflete na categoria de candidatos e de vereadores eleitos, havendo maior grau de escolarização entre aqueles que concorrem ou ocupam os cargos públicos do que entre a população em geral.

No que se refere à variável partido político, podemos destacar que dos sete maiores partidos citados por inúmeros autores, seis deles estão presente entre os dez mais expressivos na eleição de 2012 no litoral paranaense. Ainda é importante mencionar que o litoral paranaense possui um número efetivo de partidos que corresponde a 7,17, o que indica que independentemente do número de cadeiras ofertadas há um grande número de partidos efetivos.

Quanto à última variável trabalhada, ocupação, é de se ressaltar a alta predominância de ocupações de cunho público e de ocupações que possuem destaque no cenário econômico do município.

\section{REFERÊNCIAS}

AZEVEDO, Sérgio de, et.al. Mudanças e Permanências na Cultura Política das Metrópoles Brasileiras. In DADOS-Revista de Ciências Sociais, Rio de Janeiro,Vol.52, n.3, 2009, pp.691 a 733.

BAQUERO, Rute e BAQUERO, Marcello. Educando para a democracia: valores democráticos partilhados por jovens porto-alegrenses. In Ciências Sociais em Perspectiva (6) $11,2^{\circ}$ sem. 2007. 
BRASIL, Secretaria de Políticas para as Mulheres. As Mulheres nas Eleições de 2014. Brasília: Secretaria de Políticas para as Mulheres. 2014.

BRASIL, Tribunal Superior Eleitoral. Eleições no Brasil: uma história de $\mathbf{5 0 0}$ anos. Brasília: Tribunal Superior Eleitoral. 2014.

CORRALO, Giovani da Silva. O poder legislativo municipal- Aportes teóricos e práticos para a compreensão e o exercício da função parlamentar nas câmaras de vereadores. $1^{\circ}$ edição ed. São Paulo, Magalheiros, 2008.

COTTA, M. Representação política. In: BOBBIO, N.; MATTEUCCI, N. \& PASQUINO, G. (orgs.). Dicionário de política. 4ª ed. V. 2. Brasília: UNB,1992.

GOHN, Maria da Glória. Os Jovens na Política na Atualidade. In Anais do III Encontro Internacional- Participação, Democracia e Políticas Públicas. Vitória, 30 maio a 2 junho 2017.

HOROCHOVSKI, Rodrigo R. et al. Bacharelado em Gestão pública da UFPR: uma contribuição ao desenvolvimento sustentável. In Revista Temas de Administração Pública. FCLAR/UNESP. Edição Especial. V.3, n.6, 2012.

IBGE. Instituto Brasileiro de Geografia e Estatística. Disponível em: $<$ http://cidades.ibge.gov.br/xtras/uf.php?lang=\&coduf=41\&search=parana >Acesso eem 3 de novembro 2014.

IPARDES - Instituto Paranaense de Desenvolvimento Econômico e Social. Disponível <http://www.ipardes.gov.br/index.php?pg_conteudo=1\&cod_conteudo=29> em: Acesso em: 27 de abril 2015.

JÚNIOR PINTO, Nilo Ferreira. O princípio do pluralismo político e a Constituição Federal. In Revista eletrônica TER/RN, v.25, 2011. Disponível em: < http: /l www.tre-rs.gov.br/arquivos/ Acesso em: 12 de maio de 2015.

KERBAY, Maria T M. As Câmaras Municipais brasileiras: perfil de carreira e percepção sobre o processo decisório local. Opinião pública, campinas, vol, $\mathrm{XI}$, n. 2, outubro, 2005, p. 337-365. Disponível em: < http: Iwww.scielo.br/scielo.php?script=sci_arttext\&pid=S0104 > Acesso em: 18 de maio de 2015.

MIGUEL, L. F. Impasses da accountability: dilemas e alternativas da representação política. Revista de Sociologia Política, Curitiba, n. 25, p. 25-38, nov. 2005.

NICOLAU, Jairo. Partidos na república de 1946: uma réplica metodológica. Dados, Rio de Janeiro, v. 48, n. 3, p. 589-608, setembro. 2005.

NÓBREGA, Luciana N. LOPES, Ana Maria D'Avila. Democratizando a democracia: a participação política das mulheres e a reforma do sistema político. Disponível em: $<$ http: 
I/www.conpedi.org.br/manaus/.../anais/bh/ana_maria_davila_lopes2.pd> Acesso em: 12 de junho 2015.

PEREIRA, Mirian T. LOPES, Janete, L. A importância do Capital humano para o crescimento econômico. IXEPCT- Encontro de Produção Científica e Tecnologia. Campo Mourão. 27, 31 de out. 2014. Disponível em: < http: I/www www.fecilcam.br/nupem/anais_ix_epct/PDF/TRABALHOS.../04.pdf> Acesso em: 16 de abril 2015.

RIBEIRO, Pedro Floriano. Em nome da coesão: parlamentares e comissionados nas executivas nacionais dos partidos brasileiros. Revista de Sociologia e Política, [S.I.], v. 22, n. 52, p. 121-158, dez. 2014. ISSN 0067-964X. Disponível em: $\quad<$ http://ojs.c3sl.ufpr.br/ojs2/index.php/rsp/article/view/39148/24000>. Acesso em: 14 abril de 2015.

RODRIGUES, Lucas Trompieri. A fragmentação partidária e a crise de representação política. In Âmbito Jurídico, Rio Grande, XVII, n. 124, maio 2014. Disponível em: $<$ http://www.ambitojuridico.com.br/site/index.php?n_link=revista_artigos_leitura\&artigo_id=14724\&r evista_caderno=28>. Acesso em abril de 2015 .

SALVADOR, Evilasio. AMORIM, Àlvaro A Santarém. Abordagem das desigualdades socioeconômicas no Brasil do século XXI. Revista em Pauta. V, 08. N, 26, dez, 2010. Disponível em: < http: /l www.e-publicacoes.uerj.br> Acesso em: 20 de abril. 2014.

SENADO FEDERAL. Constituição Federal de 1988. Brasília: senado federal. 2004.

SOUZA, Carlos A da. Et al. Padrões geográficos da coligações eleitorais no Brasil: uma análise pela perspectiva ideológica dos partidos políticos-2002, 2006 e 2012. Disponível em: < http: II www.escavador.com/pessoas/90236 > Acesso em: 20 de abril 2015.

TSE, Tribunal Superior Eleitoral. Disponível em: <http://www.tse.jus.br/eleicoes/estatisticas/estatisticas-eleicoes-2012> Acesso em: 17 de Novembro 2014.

YOUNG, I. M. 2006. Representação política, identidade e minorias. Lua Nova, São Paulo, n. 67, p. 139-190. Disponível em: http:// www.scielo.br/pdf/ln/n67/a06n67.pdf. Acesso em; 29.dez.2010. 